\title{
Current and Voltage Mode Quadrature Oscillator Based on Voltage Differencing Buffered Amplifier
}

\author{
Abdullah Yeşil' ${ }^{1}$, Fırat Kaçar² \\ 'Department of Naval Architecture and Marine Engineering, Bandırma Onyedi Eylül University Maritime Faculty, Balıkesir, Turkey \\ ${ }^{2}$ Department of Electrical and Electronics Engineering, İstanbul University School of Engineering, İstanbul, Turkey
}

Cite this article as: A. Yeşil, F. Kaçar. "Current and Voltage Mode Quadrature Oscillator Based on Voltage Differencing Buffered Amplifier". Electrica, vol. 18, no. 1, pp. 6-12, 2018.

\section{ABSTRACT}

In this work, we present a current-mode and voltage-mode quadrature oscillator circuit using a voltage differencing buffered amplifier (VDBA), two grounded capacitors, and a grounded resistor. The oscillation condition and frequency are orthogonally (or independently) controllable. The currentmode and voltage-mode quadrature signals can be simultaneously obtained from the proposed circuit. The use of only grounded capacitors and resistors makes the proposed circuits ideal for integrated circuit implementation. The quadrature oscillator is simulated with SPICE simulation program using $0.35-\mu m$ technology parameters.

Keywords: Quadrature oscillator, CMOS active elements, non-ideal analysis, voltage mode

Address for Correspondence:

Fırat Kaçar

E-mail:

fkacar@istanbul.edu.tr

Received: 08.03 .2017

Accepted: 05.12.2017

C Copyright 2018 by Electrica

Available online at

http://dergipark.gov.tr/iujeee

DOI: 10.5152/iujeee.2018.1802

\section{Introduction}

In the design of electronic systems, the need often arises both single periodic waveform and two periodic waveforms with $90^{\circ}$ phase difference called a quadrature oscillator. Application areas of quadrature oscillator are in the communication system for quadrature mixers, in test and measurement system for testing characterizing electronic devices and circuits, in single-sideband generators or selective voltmeters [1,2]. Different kinds of active elements have been used in quadrature oscillators up to now. Designers of quadrature oscillators utilize various active elements such as the positive, negative and inverting second generation current conveyor (ICCII-, CCII+, CCII-) [3-5], current differencing transconductance amplifier (CDTA) [6-8], current differencing buffered amplifier (CDBA) [9-10], operational amplifier [11], current feedback operational amplifier (CFOA) [12-14], differential difference current conveyor (DDCC) [15], fully balanced voltage differencing buffered amplifier (FB-VDBA) [16], also known as current backward transconductance amplifier (CBTA) [17], differential difference dual-X second generation current conveyor (DD-DXCCII) [18] and four terminal floating nullor (FTFN) [19-21].

A summary of the performance parameters of compared oscillators and the proposed oscillator are shown in Table 1. It can be observed from Table 1 that the proposed oscillator possesses superior features according to recently reported oscillators.

In this paper, voltage differencing buffered amplifier (VDBA) which is attractive active element contains two basic blocks like voltage buffer and transconductance stage which can be tuned electronically biasing current. Therefore, in this paper, the VDBA is chosen to be used in the design of an electronically tunable quadrature oscillator having two voltage outputs and three current outputs. Its main advantages are the minimum number of active and passive elements and independent setting of frequency and condition of oscillations. Besides, all passive elements are grounded and the required oscillator frequency could be easily adjusted by varying the external DC bias currents of the VDBAs. 
Table 1. Comparison of the proposed oscillator with those of previous circuits

\begin{tabular}{|c|c|c|c|c|c|c|}
\hline & $\begin{array}{l}\text { Number } \\
\text { of active } \\
\text { elements }\end{array}$ & $\begin{array}{l}\text { Number } \\
\text { of passive } \\
\text { elements }\end{array}$ & $\begin{array}{l}\text { Electronically } \\
\text { adjusting oscillation } \\
\text { condition } \\
\text { independently of } \\
\text { oscillation frequency }\end{array}$ & $\begin{array}{l}\text { Types of } \\
\text { passive } \\
\text { elements' } \\
\text { tie }\end{array}$ & $\begin{array}{l}\text { Type (VM/ } \\
\text { CM) and } \\
\text { number of } \\
\text { outputs }\end{array}$ & $\begin{array}{c}\text { Frequency } \\
\text { of } \\
\text { oscillation }\end{array}$ \\
\hline Sobhy and Soliman (2007) [3]a & 3 ICCII- & $4 \mathrm{R} / 2 \mathrm{C}$ & No & Grounded & $2 \mathrm{VM}$ & $3.98 \mathrm{MHz}$ \\
\hline Khateb et al. (2012) [4] & $2 \mathrm{CCII}$ & $3 \mathrm{R} / 2 \mathrm{C}$ & No & Grounded & $2 \mathrm{CM}$ & $10 \mathrm{kHz}$ \\
\hline Yucel and Yuce (2015)[5] & 2 CCII- & $4 \mathrm{R} / 2 \mathrm{C}$ & No & Floating & $3 \mathrm{VM}$ & $4.54 \mathrm{MHz}$ \\
\hline Horng et al. (2010) [6]b & 3 CDTA & $3 C$ & Yes & Grounded & $2 \mathrm{VM} / 2 \mathrm{CM}$ & $410 \mathrm{kHz}$ \\
\hline Jin \& Wang (2014) [7] & 2 CDTA & $1 \mathrm{R} / 2 \mathrm{C}$ & Yes & Floating & $4 \mathrm{CM}$ & $240 \mathrm{MHz}$ \\
\hline Jin and Wang (2012) [8] & 1 CDTA & $1 \mathrm{R} / 2 \mathrm{C}$ & No & Floating & $2 \mathrm{CM}$ & $1.87 \mathrm{MHz}$ \\
\hline Tangsrirat et al. (2008) [9] & $2 \mathrm{CDBA}$ & $3 \mathrm{R} / 2 \mathrm{C}$ & No & Floating & $2 \mathrm{VM}$ & $15.91 \mathrm{kHz}$ \\
\hline Keskin (2005) [10] & $1 \mathrm{CDBA}$ & $2 \mathrm{R} / 2 \mathrm{C}$ & No & Floating & $1 \mathrm{VM}$ & $795.8 \mathrm{~Hz}$ \\
\hline Horng (2011) [11]C & 3 OP-AMP & $5 R / 3 C$ & No & Floating & $2 \mathrm{VM}$ & $15.91 \mathrm{kHz}^{*}$ \\
\hline Tangsrirat \& Surakamponton (2009) [12] & 2 CFOA & $3 \mathrm{R} / 2 \mathrm{C}$ & No & Floating & $2 \mathrm{VM}$ & $15.8 \mathrm{kHz}$ \\
\hline Lahiri et al. (2013) [13]d & 3 CFOA & $4 \mathrm{R} / 2 \mathrm{C}$ & No & Floating & $1 \mathrm{VM} / 2 \mathrm{CM}$ & $128.9 \mathrm{kHz}$ \\
\hline Soliman (2000) [14]e & 1 CFOA & $2 \mathrm{R} / 2 \mathrm{C}$ & No & Floating & $1 \mathrm{VM}$ & $160.9 \mathrm{kHz}$ \\
\hline Soliman (2000) [14]f & 2 CFOA & $2 \mathrm{R} / 2 \mathrm{C}$ & No & Grounded & $2 \mathrm{VM}$ & $153.43 \mathrm{kHz}$ \\
\hline Kumngern \& Dejhan (2009) [15] & 2 DDCC & $3 \mathrm{R} / 2 \mathrm{C}$ & No & Grounded & $2 \mathrm{VM}$ & $640 \mathrm{kHz}$ \\
\hline Yesil et al. (2016) [16] & 1 FB-VDBA & $1 \mathrm{R} / 2 \mathrm{C}$ & No & Floating & $2 \mathrm{VM}$ & $1.33 \mathrm{MHz}$ \\
\hline Ayten et al. (2012) [17]g & 1 CBTA & $1 \mathrm{R} / 2 \mathrm{C}$ & No & Grounded & $2 \mathrm{VM} / 1 \mathrm{CM}$ & $18.9 \mathrm{MHz}$ \\
\hline Chaturvedi, \& Mohan (2015) [18] & $\begin{array}{c}1 \text { DD- } \\
\text { DXCCII }\end{array}$ & $3 \mathrm{R} / 2 \mathrm{C}$ & No & Grounded & $3 \mathrm{VM} / 2 \mathrm{CM}$ & $15.78 \mathrm{MHz}$ \\
\hline Bhaskar and Senani (2005) [19] & 2 PFTFN & $4 \mathrm{R} / 2 \mathrm{C}$ & No & Floating & $1 \mathrm{CM}$ & $17.36 \mathrm{kHz}^{*}$ \\
\hline Kumar and Senani (2007) [20] & 1 PFTFN & $5 \mathrm{R} / 2 \mathrm{C}$ & No & Floating & $1 \mathrm{VM}$ & $4.98 \mathrm{kHz}$ \\
\hline Cam et al. (2000) [21]i & 1 FTFN & $5 \mathrm{R} / 2 \mathrm{C}$ & No & Floating & $1 \mathrm{CM}$ & $28 \mathrm{kHz}$ \\
\hline The proposed oscillator & 2 VDBA & $1 \mathrm{R} / 2 \mathrm{C}$ & Yes & Grounded & $2 \mathrm{VM} / 3 \mathrm{CM}$ & $1.14 \mathrm{MHz}$ \\
\hline \multicolumn{7}{|c|}{ 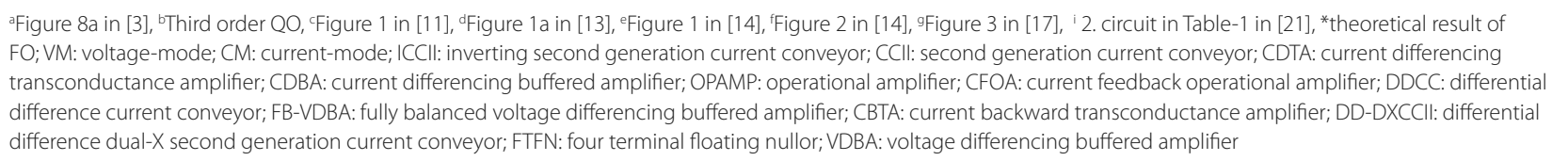 } \\
\hline
\end{tabular}

\section{Voltage Differencing Buffered Amplifier}

In the paper [22], the schematic symbol of the VDBA is added ZC- terminals, which is negative of the $Z$ terminal. Its modified schematic symbol of the VDBA is given in Figure 1.

Using standard notation, the relationship between port currents and voltages of the VDBA can be defined by the following hybrid matrix:

$$
\left(\begin{array}{l}
I_{P} \\
I_{N} \\
I_{Z} \\
I_{Z C-} \\
V_{W}
\end{array}\right)=\left(\begin{array}{ccc}
0 & 0 & 0 \\
0 & 0 & 0 \\
g_{m} & -g_{m} & 0 \\
-g_{m} & g_{m} & 0 \\
0 & 0 & \alpha
\end{array}\right)\left(\begin{array}{l}
V_{P} \\
V_{N} \\
V_{Z}
\end{array}\right)
$$

where $g_{m}$ and a represent transconductance and the non-ideal voltage gain of the VDBA, respectively. The value of $a$ in an ideal VDBA is equal to unity. It should be noted from the above 


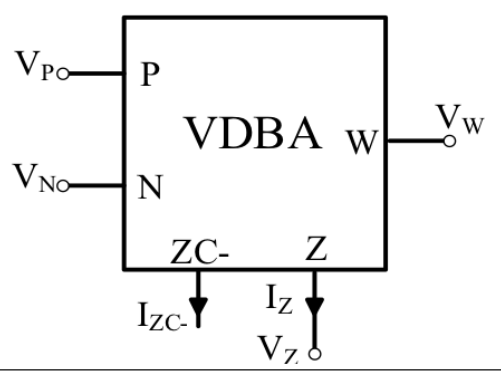

Figure 1. The circuit symbol of the VDBA

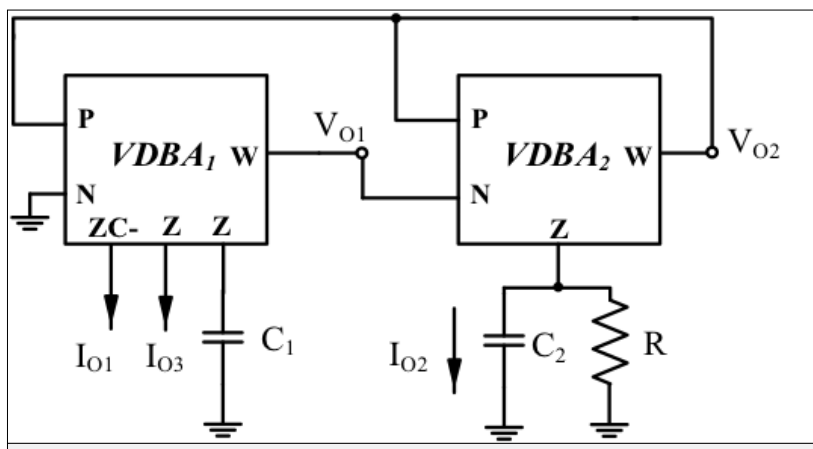

Figure 2. Proposed quadrature oscillator circuit

that it possesses $\mathrm{W}$ terminal of low impedance and other terminals of high impedance. The CMOS implementation of the VDBA consists of an operational transconductance amplifier and a voltage buffer. The current of $\mathrm{P}$ and $\mathrm{N}$ are approximated to zero. The terminal $W$ is the output of voltage buffer; thus the voltage of $\mathrm{W}$ is approximated to $\mathrm{Z}$.

\section{Proposed Quadrature Oscillator Circuit}

The proposed quadrature oscillator which is shown in Figure 2 offers two voltage outputs and three current outputs. It is made up of two VDBAs and three passive elements such as two grounded capacitors and a resistor.

The circuit analysis yields the following second order characteristic equation.

$$
s^{2} C_{1} C_{2}+s C_{1}\left(\frac{1}{R}-g_{m 2}\right)+g_{m 1} g_{m 2}=0
$$

The frequency of oscillation (FO) and the condition of oscillation (CO) are found as

$$
F O: f_{0}=\frac{1}{2 \pi} \sqrt{\frac{g_{m 1} g_{m 2}}{C_{1} C_{2}}}
$$

$C O: \quad R \cdot g_{m 2}=1$
It is apparent that FO and CO can be set independently. The relation between the two output voltages at the oscillation frequency is

$$
V_{O 1}=e^{-j 90^{\circ}} V_{O 2} k_{V M} ; \quad k_{V M}=\sqrt{\frac{g_{m 1} C_{2}}{g_{m 2} C_{1}}}
$$

This confirms that the output voltages are in quadrature and indicates that if the output voltage amplitudes are to be equal, we must choose $\mathrm{k}_{\mathrm{vM}}=1$. At the oscillation frequency it holds for the three output currents;

$$
I_{O 1}=e^{j 90^{\circ}} I_{O 2} k_{C M}=e^{j 180^{\circ}} I_{O 3} ; \quad k_{C M}=\sqrt{\frac{g_{m 1} C_{1}}{g_{m 2} C_{2}}}
$$

The currents are not only shifted by $90^{\circ}$ but also shifted by $180^{\circ}$ and they have the same amplitude if $\mathrm{k}_{\mathrm{CM}}=1 \mathrm{abstract}$

\section{Non-Ideal and Parasitic Effects Analyses}

Considering the non-ideal voltage gain a of the VDBA, the second order characteristic equation in Equation (2) convert to:

$$
s^{2} C_{1} C_{2}+s C_{1}\left(\frac{1}{R}-g_{m 2} \alpha_{2}\right)+g_{m 1} g_{m 2} \alpha_{1} \alpha_{2}=0
$$

and non-ideal FO and the $\mathrm{CO}$ are given as:

$$
F O: f_{0}=\frac{1}{2 \pi} \sqrt{\frac{g_{m 1} g_{m 2} \alpha_{1} \alpha_{2}}{C_{1} C_{2}}}
$$

$C O: \quad R \cdot g_{m 2}=\alpha_{2}$

From Equations (7a) and (7b), the tracking errors slightly change the FO and CO. However, the FO and CO still can be adjusted. Also, the non-ideal relation between the two output voltages at the oscillation frequency is

$$
V_{O 1}=e^{-j 90} k_{1} V_{O 2} ; \quad k_{1}=\sqrt{\frac{g_{m 1} C_{2} \alpha_{1}}{g_{m 2} C_{1} \alpha_{2}}}
$$

It is clear from equation (8) that the phase difference between $\mathrm{V}_{\mathrm{O} 1}$ and $\mathrm{V}_{\mathrm{O} 2}$ is $-90^{\circ}$ under the sinusoidal steady state. In other words, its output voltages are in quadrature. It is seen from Equation (8) that the output voltages have to equal to amplitude for $k_{1}=1$. The non-ideal relationships among the current outputs are also given below at Equation (9);

$I_{O 1}=e^{j 90} k_{2} I_{O 2}=e^{j 180} I_{O 3} ; \quad k_{2}=\sqrt{\frac{g_{m 1} C_{1} \alpha_{2}}{g_{m 2} C_{2} \alpha_{1}}}$

Similarly, It is obvious from Equation (9) that not only the outputs of current have to equal to amplitude for $k_{2}=1$ but also phase difference among the current outputs are $90^{\circ}$. Note that, in order to obtain the $\mathrm{I}_{\mathrm{O} 2}$ current output through the capacitor, CCII- can be easily preferred by grounding $Y$ terminal and using $X$ and $Z$ as input and output, respectively. By taking into account the parasitic effects of the VDBA, Figure 3 depicts parasitic effects of the proposed quadrature oscillator circuit. 


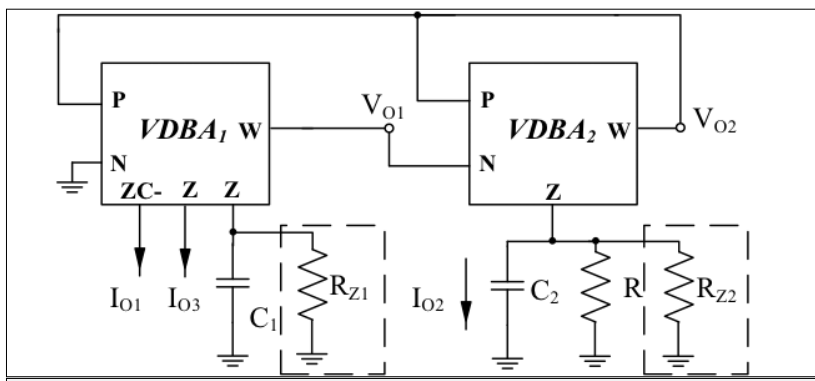

Figure 3. Parasitic impedances of VDBA affecting oscillator circuit

$R_{z 1}$ and $R_{z 2}$ are the parasitic resistance of $Z$ terminal of VDBA which belongs $i^{\text {th }}$ the VDBA. $R_{\mathrm{z} 1}$ and $\mathrm{R}_{\mathrm{z} 2}$ are the mainly parasitic elements for the proposed oscillator circuit. Reanalyzing the oscillator circuit shown in Figure 3 yields the following modified second order characteristic equation;

$$
\begin{aligned}
& s^{2} C_{1} C_{2}+s\left(\frac{C_{1}}{R / / R_{Z 2}}+\frac{C_{2}}{R_{Z 1}}-C_{1} g_{m 2}\right) \ldots \\
& +g_{m 1} g_{m 2}+\frac{1}{R_{Z 1} R_{Z 2} / / R}-\frac{g_{m 2}}{R_{Z 1}}=0
\end{aligned}
$$

The parameter of the modified FO and the modified CO can be expressed as follows;

$$
\begin{aligned}
& F O: f_{0}=\frac{1}{2 \pi} \sqrt{\frac{g_{m 1} g_{m 2}}{C_{1} C_{2}}+\frac{1}{C_{1} C_{2} R_{Z 1} R_{Z 2} / / R}-\frac{g_{m 2}}{C_{1} C_{2} R_{Z 1}}} \\
& C O: \quad C_{1} g_{m 2}=\frac{C_{1}}{R / / R_{Z 2}}+\frac{C_{2}}{R_{Z 1}}
\end{aligned}
$$

The value of the modified FO and CO may be altered slightly by parasitic effects of VDBA. To minimize the deviation of the FO, output resistance of $Z$ terminal of the VDBA should be increased by using cascode current mirror for the first stage of VDBA.

\section{Simulation Results}

So as to confirm the theoretical results of the proposed quadrature oscillator circuit, Figure 2 has been simulated using SPICE simulation program. According to previous version [22], the modified CMOS implementation of VDBA is depicted in Figure 4. The aspect ratios of the CMOS transistors used in the modified VDBA are given in Table 2.The supply voltages, biasing voltage and current are chosen as $\mathrm{V}_{\mathrm{DD}}=-\mathrm{V}_{\mathrm{SS}}=1.5 \mathrm{~V}, \mathrm{~V}_{\mathrm{B}}=-0.9 \mathrm{~V}$, and $I_{B}=100 \mu A$.

Table 2. Transistors aspect ratios for the modified VDBA

\begin{tabular}{lcc}
\hline Transistors & $\mathbf{W}(\boldsymbol{\mu m})$ & $\mathbf{L}(\boldsymbol{\mu m})$ \\
\hline$M_{1}-M_{4^{\prime}} M_{18}-M_{21}$ & 7 & 0.35 \\
\hline$M_{5}-M_{8}$ & 21 & 0.7 \\
\hline$M_{9}-M_{12}$ & 7 & 0.7 \\
\hline$M_{13}-M_{14}$ & 3.5 & 0.7 \\
\hline$M_{15}-M_{17}$ & 14 & 0.35 \\
\hline
\end{tabular}

VDBA: voltage differencing buffered amplifier

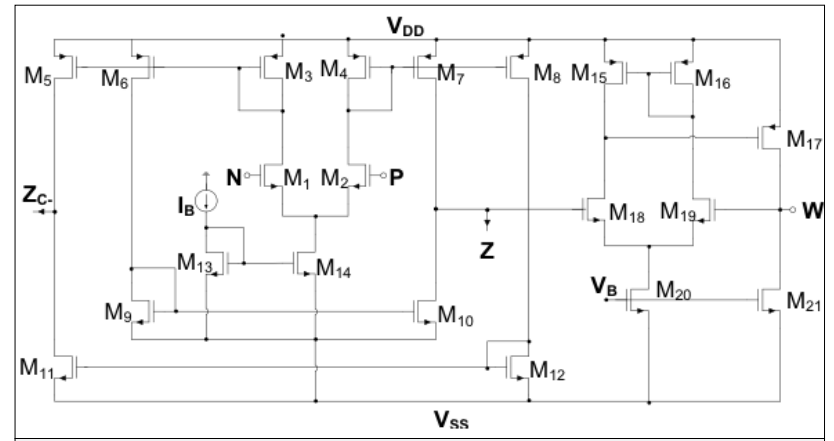

Figure 4. The modified CMOS structure for the VDBA

The quadrature oscillator has been built with $\mathrm{C}_{1}=\mathrm{C}_{2}=100 \mathrm{pF}$, $\mathrm{g}_{\mathrm{m} 1}=\mathrm{g}_{\mathrm{m} 2}=735 \mu \mathrm{A} / \mathrm{V}$ and $\mathrm{R}=1.4 \mathrm{k} \Omega$ which is slightly bigger than the value $1.36 \mathrm{k} \Omega$ calculated from $\mathrm{CO}$. This is to ensure that oscillations would start. The theoretical FO is calculated as $f_{o}=1.17 \mathrm{MHz}$. The simulated FO obtained from the simulation results is measured as $1.14 \mathrm{MHz}$. the slightly discrepancy between simulation and theoretical resutls stems from limited frequency bandwidth of the transconductance and voltage transfer gain error, and parasitic effects. The simulated output waveforms of the quadrature voltages are demostrated in Figure 5, whereas Figure 6 depicts the spectrum of the oscillator output voltages. As it is seen from Figure 6, voltage outputs, $\mathrm{V}_{\mathrm{O} 1}$ and $\mathrm{V}_{\mathrm{O}^{\prime}}$ of the proposed oscillator provide $52.2 \mathrm{~dB}$ and $48.1 \mathrm{~dB}$ of rejection at the second harmonic, respectively.

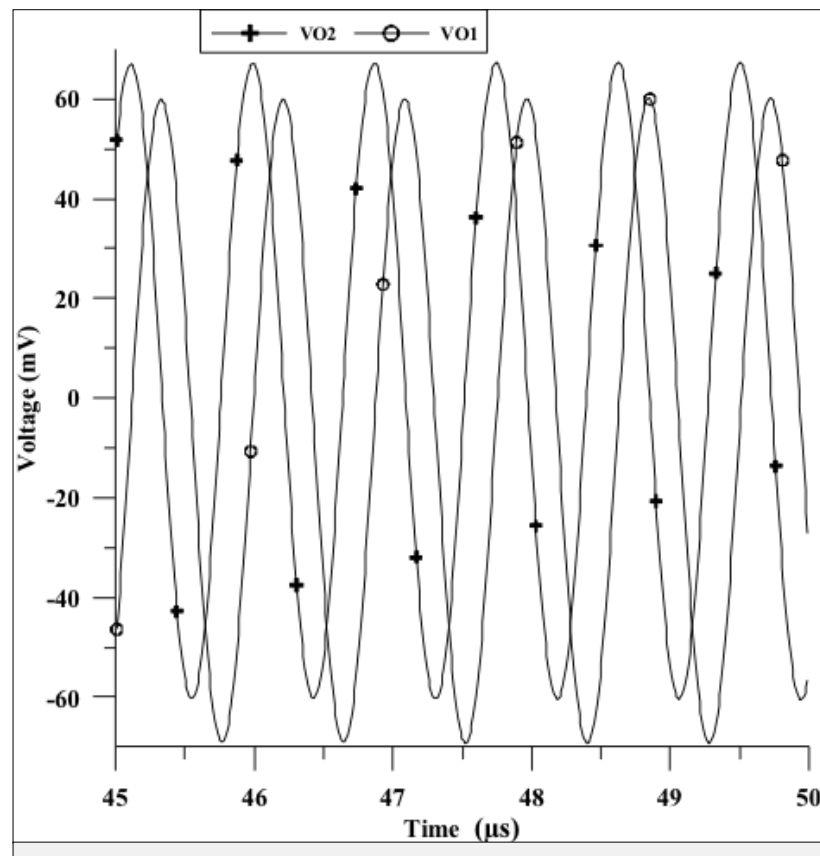

Figure 5. The steady-state waveforms for the quadrature voltages $\mathrm{V}_{\mathrm{O} 1}$ and $\mathrm{V}_{\mathrm{O} 2}$

The waveforms of the oscillator output currents are illustrated in Figure 7, whereas Figure 8 depicts the spectrum of the 

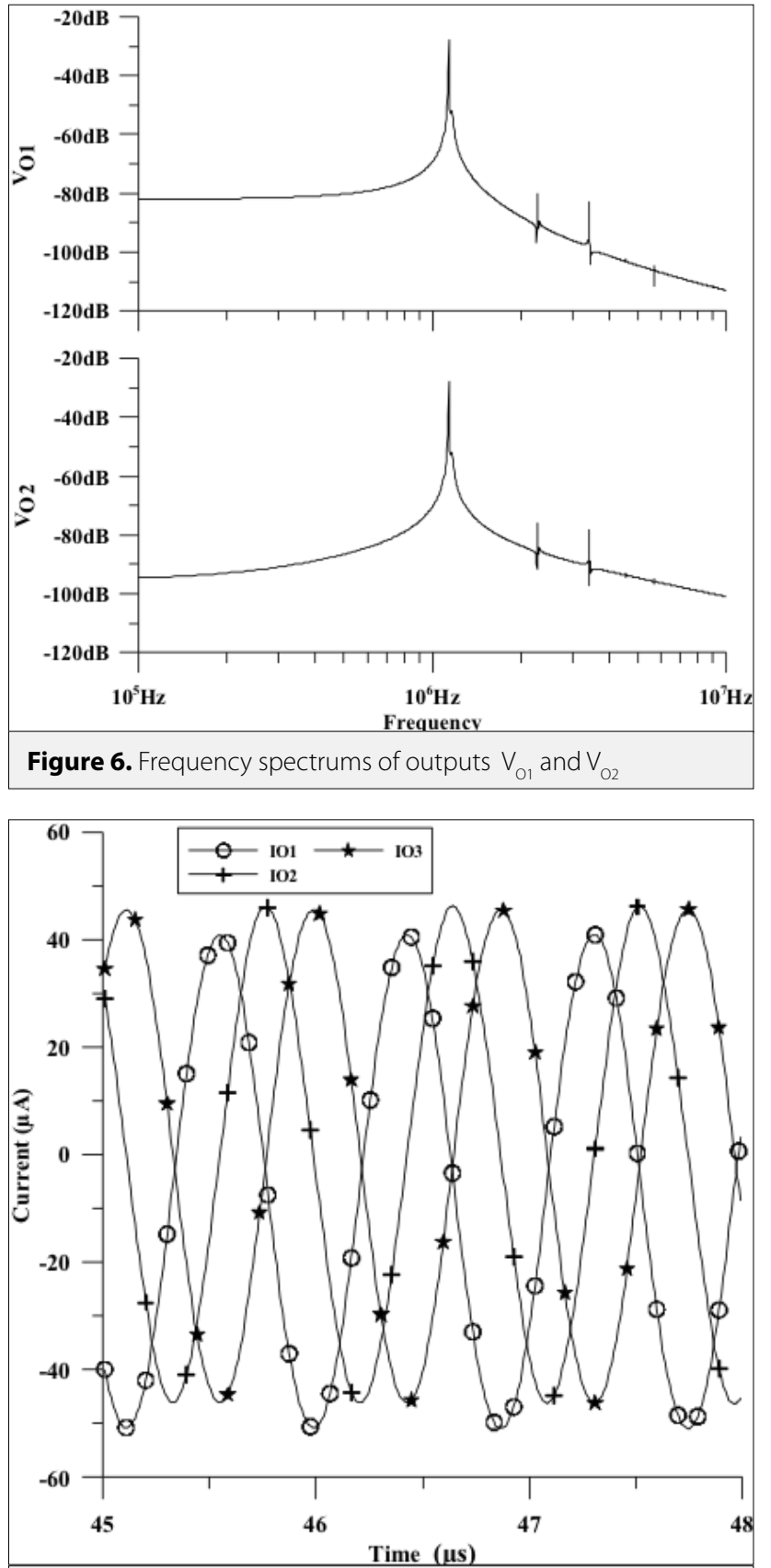

Figure 7. The steady-state waveforms for the quadrature currents $\mathrm{I}_{\mathrm{O} 1}, \mathrm{I}_{\mathrm{O} 2}$, and $\mathrm{I}_{\mathrm{O} 3}$

oscillator output currents. As it is seen from Figure 8, second harmonic rejection ratios of current outputs, $\mathrm{I}_{\mathrm{O} 1}, \mathrm{I}_{\mathrm{O} 2}$, and $\mathrm{I}_{\mathrm{O} 3}$ are around $47.4 \mathrm{~dB}, 45 \mathrm{~dB}$, and $48.5 \mathrm{~dB}$, respectively. The total harmonic distortion (THD) is $0.33 \%$ for voltage output $\mathrm{V}_{01}, 0.52 \%$ for voltage output $\mathrm{V}_{\mathrm{O} 2}, 0.87 \%$ for current output $\mathrm{I}_{\mathrm{O} 1}, 1.4 \%$ for current output $\mathrm{I}_{\mathrm{O} 2}$ and $0.84 \%$ for current output $\mathrm{I}_{\mathrm{O} 3}$.

In order to change electronically oscillation frequency, transconductance value $\left(g_{m 1}\right)$ of first VDBA element is tuned by the means of $I_{B}$ biasing current. Variation of between oscillation
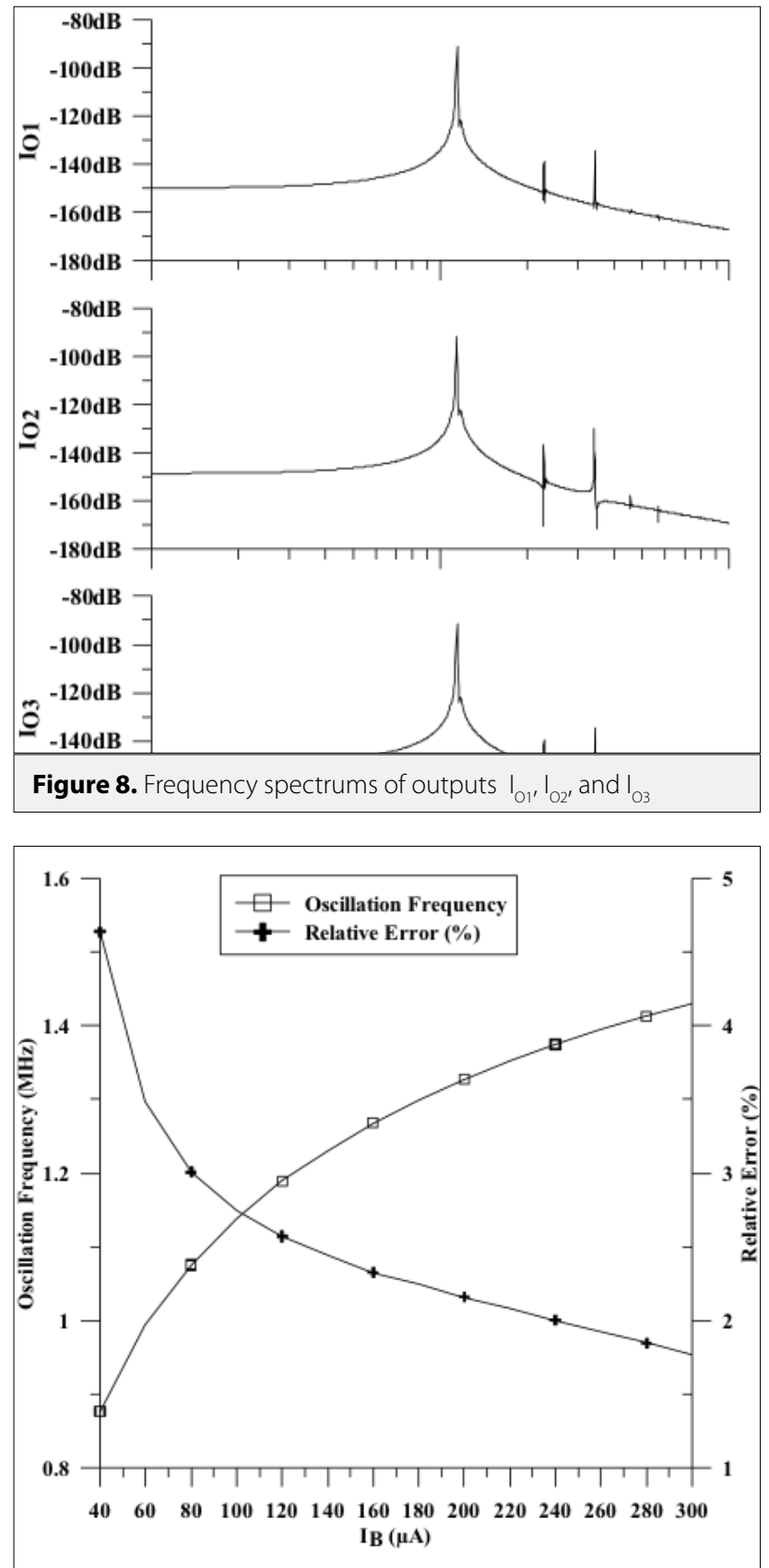

Figure 9. Variations of oscillation frequency and relative error via IB biasing current

frequency and $I_{B}$ biasing current is given in Figure9. Moreover, the definition of percentage relative error can be described by the following equation;

$\%$ Relative Error $=100 \frac{f_{\text {Theoretical }}-f_{\text {Simulation }}}{f_{\text {Theoretial }}}$

Variation of between $I_{B}$ biasing current and percentage relative error value is also depicted in Figure9. It can be observed from Figure 9 that percentage relative error is decreased with increasing biasing current $\left(I_{B}\right)$. 


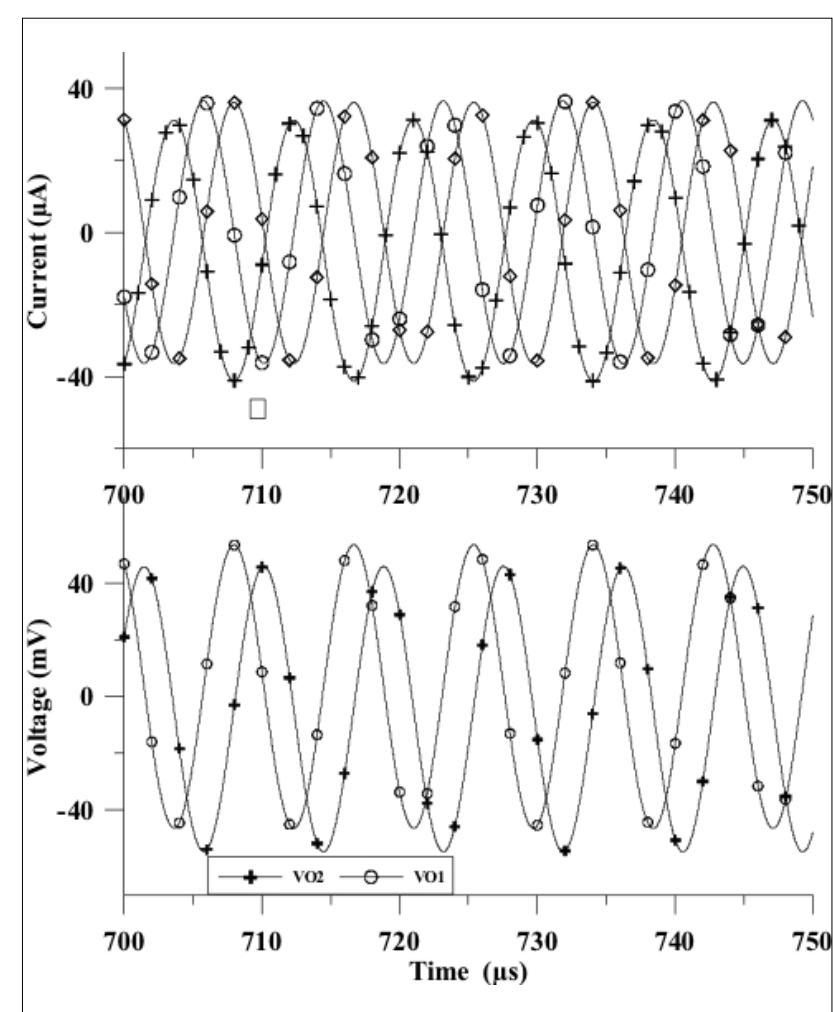

Figure 10. The steady-state waveforms for voltage and current outputs

So as to survey the performance of the proposed quadrature oscillator at low frequencies, external capacitances values are chosen as $1 \mathrm{nF}$ to obtain frequency oscillation of $f_{0}=114 \mathrm{kHz}$. The steady-state waveforms for voltage and current outputs are depicted in Figure 10. THDs of voltage outputs $\left(\mathrm{V}_{\mathrm{O} 1}\right.$ and $\mathrm{V}_{\mathrm{O} 2}$ ) are calculated as $0.23 \%$ and $0.35 \%$, respectively, whereas THDs of current outputs $\left(\mathrm{I}_{\mathrm{O} 1}, \mathrm{I}_{\mathrm{O} 2}\right.$, and $\left.\mathrm{I}_{\mathrm{O} 3}\right)$ are calculated as $0.58 \%$, $0.89 \%$, and $0.56 \%$, respectively.

The behaviors of the CMOS implementation of VDBA in Figure 4 with respect to capacitors and resistor have been appreciated with the help of statistical analysis results by using the well-known Monte Carlo analysis. Monte Carlo simulation is carried out one hundred times for proposed oscillator circuit in Figure 2. The Monte Carlo analyses having 5\% Gauss deviation of capacitors and $1 \%$ Gauss deviation of the resistor are obtained as in Figure 11 where FO and THD of $\mathrm{V}_{\mathrm{O} 1}$ variations of the proposed oscillator circuit in Figure 2 are given.

\section{Conclusions}

New electronically tunable quadrature oscillator having a minimum number of active and passive elements is presented. It based on VDBA exhibits two voltage outputs and three current outputs. The influence of non-ideal effects of the VDBAs on the oscillator functionality has been investigated. Furthermore,
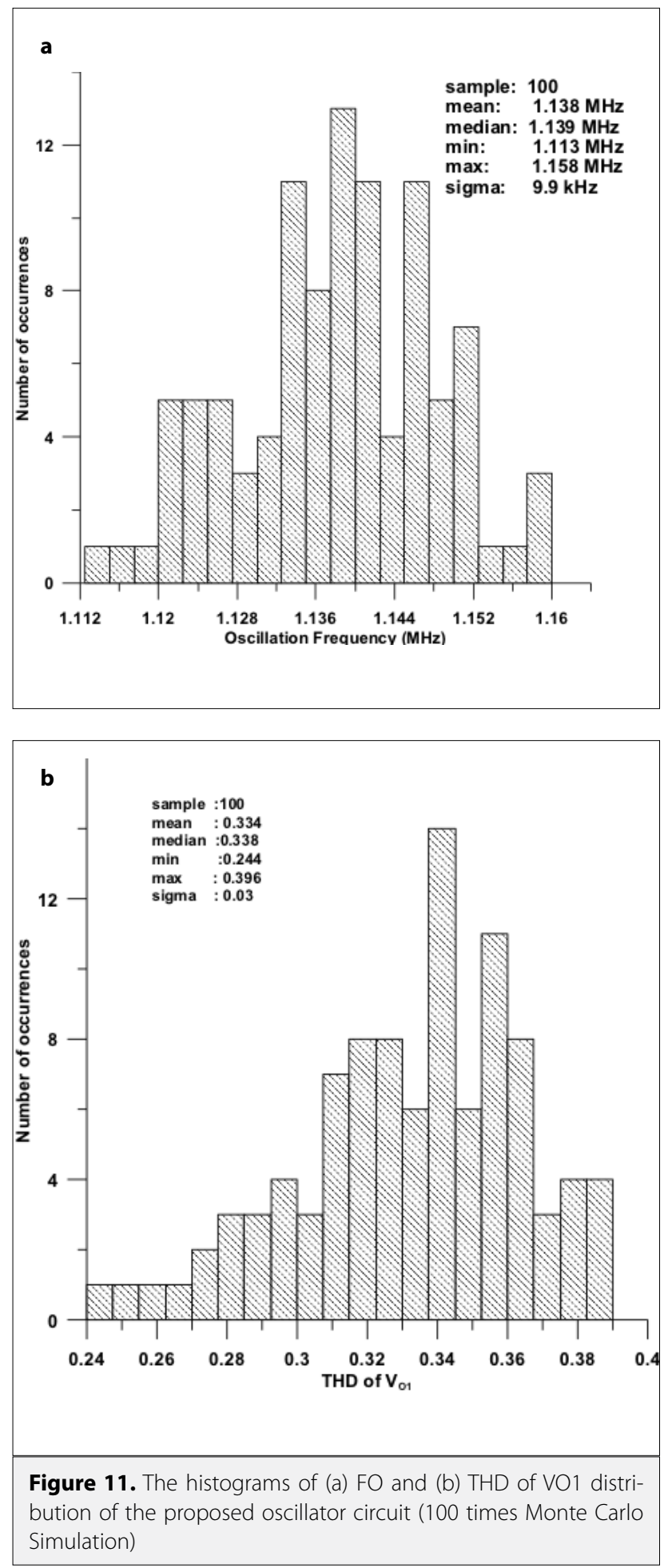

the behaviors of the CMOS implementation of VDBA in Figure 4 with respect to passive elements have been evaluated and variation of between oscillation frequency and biasing current has also been given. It is easily observed simulation results that the proposed circuit enjoys low THD, feasibility of circuit and adjustment in a wide range. 


\section{Electrica 2018; 18(1): 6-12 \\ Yeşil and Kaçar. CM and VM Quadrature Oscillator Based on VDBA}

\section{References}

1. A. S. Sedra, K. C. Smith, "Second-generation current conveyor and its applications," IEEE Trans Circuit Theory, vol. 17, pp. 132-134, 1970. [CrossRef]

2. C. Toumazou, F. J. Lidgey, D. G. Haigh, "Analogue IC design: The current mode approach," IEE circuits and systems, Peter Peregrinus, 1990.

3. E. A. Sobhy, A. M. Soliman, "Novel CMOS realizations of the inverting second-generation current conveyor and applications," Analog Integrated Circuits and Signal Processing, vol. 52, pp. 57-64, 2007. [CrossRef]

4. F. Khateb, N. Khatib, D. Kubanek, "Low-voltage ultra-low-power current conveyor based on quasi-floating gate transistors," Radioengineering, vol. 21 no. 2, pp. 725-735, 2012.

5. F. Yucel, E. Yuce "A new, single CCII-based, voltage-mode, first-order, all-pass filter and its quadrature oscillator application," Scientia Iranica. Transaction D, Computer Science \& Engineering, Electrical vol. 22 no. 3, pp. 1068-1076, 2015.

6. J. W. Horng, H. Lee, J. Y. Wu “Electronically tunable third-order quadrature oscillator using CDTAs," Radioengineering, vol. 19 no. 2 , pp. 326-330, 2010.

7. J. Jin, C. Wang, "CDTA-based electronically tunable current-mode quadrature oscillator," International Journal of Electronics, vol. 101, no. 8, pp. 1086-1095, 2014. [CrossRef]

8. J. Jin, C. Wang "Single CDTA-based current-mode quadrature oscillator," AEU-International Journal of Electronics and Communications, vol. 66, no. 11, pp. 933-936, 2012. [CrossRef]

9. W. Tangsrirat, D. Prasertsom, T. Piyatat, W. Surakampontorn, "Single-resistance-controlled quadrature oscillator using current differencing buffered amplifiers," International Journal of Electronics, vol. 95, no. 11, pp. 1119-1126, 2008. [CrossRef]

10. A.Ü. Keskin, "Voltage-mode high-Q band-pass filters and oscillators employing single CDBA and minimum number of components," International Journal of Electronics, vol. 92, no. 8, pp. 479487, 2005. [CrossRef]

11. J.W. Horng "Quadrature oscillators using operational amplifiers," Active and Passive Electronic Components, (2011). [CrossRef]
12. W. Tangsrirat, W. Surakampontorn "Single-resistance-controlled quadrature oscillator and universal biquad filter using CFOAs," AEU-International Journal of Electronics and Communications, vol. 63, no. 12, pp. 1080-1086, 2009. [CrossRef]

13. A. Lahiri, W. Jaikla, M. Siripruchyanun, "First CFOA-based explicit-current-output quadrature sinusoidal oscillators using grounded capacitors," International Journal of Electronics, vol. 100, no. 2, pp. 259-273, 2013. [CrossRef]

14. A. M. Soliman, "Current feedback operational amplifier based oscillators," Analog Integrated Circuits and Signal Processing, vol. 23, no. 1, pp. 45-55, 2000. [CrossRef]

15. M. Kumngern, K. Dejhan, "DDCC-based quadrature oscillator with grounded capacitors and resistors," Active and Passive Electronic Components, (2009). [CrossRef]

16. A. Yesil, F. Kacar, K. Gurkan "Design and Experimental Evaluation of Quadrature Oscillator Employing Single FB-VDBA," Journal of Electrical Engineering, vol.67, no. 2, pp.137-142, 2016 [CrossRef]

17. U. E. Ayten, M. Sagbas, H. Sedef, "Electronically tunable sinusoidal oscillator circuit with current and voltage outputs," International Journal of Electronics, vol. 99, no. 8, pp. 1133-1144, 2012. [CrossRef]

18. B. Chaturvedi, J. Mohan, "Single active element based mixedmode quadrature oscillator using grounded components," IU-Journal of Electrical \& Electronics Engineering, vol. 15, no. 1, pp. 1897-1906, 2015.

19. D. R. Bhaskar, R. Senani, "New FTFN-based grounded-capacitor SRCO with explicit current-mode output and reduced number of resistors," AEU-International Journal of Electronics and Communications, vol. 59, no. 1, pp. 48-51, 2005.[CrossRef]

20. P. Kumar, R. Senani, "Improved grounded-capacitor SRCO using only a single PFTFN," Analog Integrated Circuits and Signal Processing, vol. 50, no. 2, pp. 147-149, 2007. [CrossRef]

21. U. Cam, A. Toker, O. Cicekoglu, H. Kuntman, "Current-mode high output impedance sinusoidal oscillator configuration employing single FTFN," Analog Integrated Circuits and Signal Processing, vol. 24, no. 3, pp. 231-238, 2000. [CrossRef]

22. F. Kacar, A. Yesil, A. Noori, “New CMOS realization of voltage differencing buffered amplifier and its biquad filter applications," Radioengineering, vol. 21, no. 1, pp. 333-339, 2012.

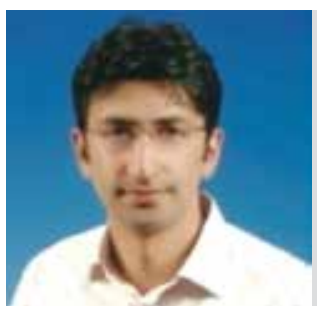

Abdullah Yeşil received his B.Sc., M.Sc. and Ph.D. degrees from İstanbul University, all in Electrical and Electronics Engineering 2009, 2011 and 2016. He is currently an assistant professor at Naval Architecture and Marine Engineering Department of Bandirma Onyedi Eylul University. His main research interests are active network synthesis, current-mode circuit design, low-noise implementation of continuous time filters, MOS-only filter design, electronic circuits for computer aided design and memristor.

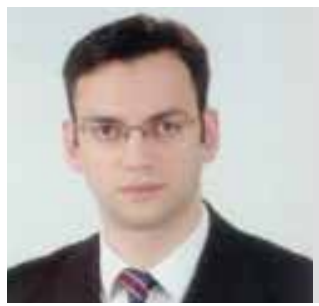

Fırat Kaçar received his B.Sc., M.Sc. and Ph.D. degrees from İstanbul University, all in Electrical and Electronics Engineering 1998, 2001 and 2005. He is currently an professor at the Electrical and Electronics Engineering Department of İstanbul University. His current research interests include analog circuits, active filters, synthetic inductors, CMOS based circuits electronic device modeling and hot-carrier effect on MOS transistor. 